\title{
LAYER THICKNESS PERFORMANCES OF COATINGS ON MDF: POLYURETHANE AND CELLULOSIC PAINTS
}

\author{
Emine Seda Erdinler ${ }^{1, \$}$, Kucuk Huseyin Koc ${ }^{2}$, Tuncer Dilik ${ }^{3}$, Ender Hazir ${ }^{4}$
}

\begin{abstract}
Furniture from wood material is exposed to various external effects. Impact has negative influence on these materials. Surface treatment is effective on wood material's durability. This may change due to layers of paint and the property of the paint used on the material. The aim of this study is to determine the differences by investigating the deformations occurring on Medium Density Fiberboard (MDF) with various surface treatments due to impact. Determination of the deformation values were performed by pendulum hardness test and rapid deformation test on MDF using polyurethane and cellulosic paints with different number of application layers. Impact tester was used for determining the effect of rapidly deforming sudden impacts. Pendulum hardness tester was used to determine the layer hardness of the surfaces. Statistical assessment was performed for determining and revealing the impacts. As result of the study, paint type, layer thickness and the interaction between them were significant. Highest layer hardness values for cellulosic paint application type 1 and polyurethane paint type 2 were 241,667 s and 222,133 s respectively. According to rapid deformation test it was determined that polyurethane paint application had better results than cellulosic paint application.
\end{abstract}

Keywords: Impact, rapid deformation, pendulum hardness test, surface treatment, wood based panel.

\section{INTRODUCTION}

MDF is a material with an increasing importance in its use. MDF is one of the materials that the manufacturers have used for years. Wood based materials such as fiberboard have a wide place of use in furniture industry. Type of coating and the quality of surface are the most significant factors affecting the overall quality of a product (Ahola 1991, de Moura and Hernandez 2006, Ramananantoandro et al. 2018, Salca et al. 2017). Coating type is important mainly on bonding, UV resistance, layer hardness, abrasion resistance and layer thickness (Salca et al. 2016, Nejad and Cooper 2011, Darmawan et al. 2018, Sogutlu et al. 2016). The most popular method for improving the stability and appearance of wood-based materials is the coating applications. These applications are effective on performance of the products mostly extending the service life and properties for the place of use (Landry et al. 2013, Cool and Hernandez 2011). The application method and the quality of the application of coatings is important as it may lead to increasing the overall cost of the products and decreasing coating performance of surfaces (Acda et al. 2012, Dilik et al. 2015, Gurleyen et al. 2017, Nejad et al. 2012). Adhesion strength of particleboard and MDF finished with cellulosic and polyurethane based paints was studied by Dilik et al. (2015) and the highest adhesion strength value was determined as 3,63 MPa for polyurethane coated MDF.

In another study by Jocham et al. (2011), pre-heating process was performed to improve the powder application in powder coating process for MDF. Board temperature and moisture content were found as the effective parameters improving the coating performance.

According to Pavlic et al. (2004), the surface treatment systems give different results. For this reason, the

\footnotetext{
1,2,3,4Faculty of Forestry, Department of Forest Industry Engineering, Istanbul University-Cerrahpasa, Istanbul, Turkey. seda@istanbul. edu.tr, hkoc@istanbul.edu.tr, tuncerd@istanbul.edu.tr, ender.hazir@istanbul.edu.tr

"Corresponding author: seda@istanbul.edu.tr

Received: 16.11.2017 Accepted: 20.12.2018
} 
systems should be tested and the appropriate system should be selected due to the result of these tests in order to obtain a high quality surface treatment result. Both in solid wood, being a heterogeneous material with a complex morphological surface structure, and wood based materials appropriate thickness of the coating film is important for the durability (Hysek et al. 2018, Montero et al. 2015, Gorgun and Dundar 2018, Evans et al. 2015). Resistance to impact is one of these test methods. It is used for determining the damages caused by the impacts during the use of impact test with various application methods, it is important to determine the best method (Nejad et al. 2013, Kaygin and Akgun 2008, Keskin and Tekin 2011, Pandey and Sirinivas 2015). Impact tests evaluate the effects of accidental contact damage that may occur in the place of use. The tests are carried out by the direct evaluation of the effect of a falling object, sphere or dart of specified shape and hardness, onto the test surface from different heights. During impact on coated surfaces, the deformation of the substrate can be relevant, significantly affecting the results. It is of importance that the coating film is flexible enough to withstand, to a certain extent, the stretching at the fringes of the deformation without any cracking or cleavage. Hardness is the ability of a coating film to resist indentation or penetration by a solid object. Hardness is also related to the drying state of coating depending on solvents retention and for chemical drying coatings, on the cross-linking effectiveness. The efficiency of the drying systems is then fundamental to achieve an adequate hardness (Bulian and Graystone 2009).

Coating process such as cellulosic, polyurethane and water base provides a protective and decorative film for wood-based material surface. Especially, polyurethane applications have some advantages such as flexibility, abrasion resistance, chemical resistance, good adhesion, fast drying and non-yellowing (Bulian and Graystone 2009) In these reasons, polyurethane coated performance better than another coating materials. Therefore, this application is widely using in the furniture industry.

The aim of this study is to determine the deformation differences on MDF performing pendulum hardness test and rapid deformation test coated with polyurethane and cellulosic paints with different number of application layers.

\section{MATERIALS AND METHODS}

In the study, MDF material is selected as the wooden panel as it is of high demand in the furniture industry. Commercially manufactured MDF panels were supplied by a local manufacturer. Density levels of MDF specimens were measured using randomly cut specimens with $50 \mathrm{~mm}^{2}$ x $50 \mathrm{~mm}^{2}$. Each specimen was weighed and its dimensions were measured at an accuracy level of $0,1 \mathrm{~g}$ and $0,01 \mathrm{~mm}$ respectively. Average density levels of MDF specimens were $730 \mathrm{~kg} / \mathrm{m}^{3}$. Surface treatment was applied with commercial cellulosic and polyurethane paints in different layer thicknesses. These paint types are widely used in furniture industry and decoration applications. Cellulosic paints are traditional paints commonly used in the industry for their reasonable prices. Polyurethane paints form a flexible layer on the surface and have properties in terms of physical and mechanical properties of wood. Specimens were coated employing a spray gun using a pressure of $0,80 \mathrm{MPa}$ at a spread rate of $120 \mathrm{~g} / \mathrm{m}^{2}$. Sequential application of primer and topcoat of the finishes were applied to the surface of each panel with an angle of 90 degrees. After each application, the layer thicknesses of the coats were measured with PosiTector Probe 200. The layer thicknesses were prepared as three-layer, fourlayer and five-layer specimens. The selected materials and their specifications are shown in (Table 1) which displays specifications of commercially manufactured interior solvent-based cellulosic and polyurethane paints. Specimens were conditioned in a climate room with a temperature of $20^{\circ} \mathrm{C}$ and relative humidity of $65 \%$ until they reach a moisture content of $12 \pm 1 \%$ before they were coated with two types of finishes. The surface treatment application plan carried out is shown in (Table 2). 
Table 1: Specifications of the finishing materials used for experiments.

\begin{tabular}{|c|c|c|c|}
\hline Paint Type & Density $\left(\mathbf{g} / \mathbf{c m}^{\mathbf{3}}\right)$ & Solid content(\%) & Viscosity (DIN6.sn) \\
\hline \multicolumn{4}{|c}{ Cellulosic base } \\
\hline Primer coating & 1,3 & 58 & 60 \\
\hline Top coat & 0,98 & 44 & 130 \\
\hline \multicolumn{5}{r}{ Polyurethane base } \\
\hline Trimer coating & 1,42 & 77 & 115 \\
\hline Top coat & 1,18 & 50 & 290 \\
\hline
\end{tabular}

Table 2: Surface treatment application plan.

\begin{tabular}{|c|c|c|}
\hline \multirow{2}{*}{ Finish Type } & $\begin{array}{c}\text { No. of } \\
\text { Sample }\end{array}$ & Finishing Process \\
\hline \multirow{3}{*}{$\begin{array}{c}\text { Cellulosic } \\
\text { Paint }\end{array}$} & 15 & $\begin{array}{c}\text { Application } 1 \\
\text { (primer+primer+top coat) }\end{array}$ \\
\cline { 2 - 3 } & 15 & $\begin{array}{c}\text { Application 2 } \\
\text { (primer+primer+top coat+top coat) }\end{array}$ \\
\hline \multirow{3}{*}{$\begin{array}{c}\text { Polyurethane } \\
\text { Paint }\end{array}$} & 15 & $\begin{array}{c}\text { Application 3 } \\
\text { (primer+primer+top coat+top coat }+ \text { top coat) }\end{array}$ \\
\cline { 2 - 3 } & 15 & $\begin{array}{c}\text { Application 1 } \\
\text { (primer+primer+top coat) }\end{array}$ \\
\cline { 2 - 3 } & 15 & $\begin{array}{c}\text { Application 2 } \\
\text { (primer+primer+top coat }+ \text { top coat) }\end{array}$ \\
\hline
\end{tabular}

In this study, two-component polyurethane paints were applied on MDF surfaces. The first component includes a polyol with an alkyd or a hydroxyl functional acrylic resin. Second component includes a polyisocyanete with two or more isocyanate groups. Another coated material for MDF surface is cellulosic paint including polymer built up from glucose units. These glucose units make up three free hydroxyl groups: (1) Cellulose esters containing cellulose acetate butyrate (CAB) and cellulose acetate propionate (CAP); (2) Cellulose nitrate (3) Cellulose ethers.

The main variables of the study were determined as the surface treatment material and the application method. In this context, the relations of impact-deformation for different thicknesses were studied. Pendulum Hardness Tester (ASTM D-4366-95 1984) was used for determining the effect of surface layer thickness on surface hardness. Test specimens were placed on the panel table and a pendulum was placed on the panel surface. The pendulum was then deflected through $6^{\circ}$ and released starting the oscillation counter.

Rapid-Deformation test was performed according to ISO 4211-4 2017. Steel ball with a diameter of 14 $\mathrm{mm}$ was dropped freely with a weight of $500 \mathrm{~g}$ from the standardized heights on the sample surface. The deformations were observed and the resistances were determined representing impact value from 1 to $5 ; 1$ referring to holes, cracks and peel offs for non-resistant coating and 5 referring to no changes for resistant coating. (Table 3) displays layer hardness, layer thickness and impact values of the specimens with cellulosic and polyurethane based paints for different application types. 
Table 3: Layer hardness, coating thickness and impact values for finish types and application types.

\begin{tabular}{|c|c|c|c|c|c|c|}
\hline \multicolumn{4}{|c|}{ Cellulosic Paint } & \multicolumn{3}{|c|}{ Polyurethane Paint } \\
\hline $\begin{array}{l}\text { Application } \\
\text { Type }\end{array}$ & $\begin{array}{c}\text { Coating } \\
\text { Thickness }(\mu)\end{array}$ & $\begin{array}{l}\text { Hardness } \\
\text { Value (s) }\end{array}$ & $\begin{array}{l}\text { Impact } \\
\text { Value }\end{array}$ & $\begin{array}{c}\text { Coating } \\
\text { Thickness } \\
(\mu)\end{array}$ & $\begin{array}{l}\text { Hardness } \\
\text { Value (s) }\end{array}$ & $\begin{array}{c}\text { Impact } \\
\text { Value }\end{array}$ \\
\hline \multirow{15}{*}{1} & 178,2 & 243 & 3 & 165,1 & 216 & 4 \\
\hline & 179,4 & 241 & 3 & 168,9 & 214 & 4 \\
\hline & 177,1 & 242 & 3 & 167,3 & 214 & 4 \\
\hline & 181 & 241 & 3 & 165,7 & 210 & 4 \\
\hline & 180,2 & 239 & 3 & 168,3 & 211 & 4 \\
\hline & 179,9 & 238 & 3 & 164,7 & 210 & 4 \\
\hline & 178,4 & 243 & 3 & 166,3 & 212 & 4 \\
\hline & 180 & 242 & 3 & 168,8 & 213 & 4 \\
\hline & 178,7 & 242 & 3 & 170,1 & 214 & 4 \\
\hline & 177,8 & 241 & 3 & 169,3 & 212 & 4 \\
\hline & 179 & 243 & 3 & 168,5 & 214 & 4 \\
\hline & 179,1 & 242 & 3 & 166,3 & 209 & 4 \\
\hline & 179 & 240 & 3 & 165,3 & 210 & 4 \\
\hline & 178,2 & 239 & 3 & 167,4 & 214 & 4 \\
\hline & 179,3 & 248 & 3 & 168,3 & 208 & 4 \\
\hline \multirow{15}{*}{2} & 181 & 231 & 2 & 238,4 & 222 & 5 \\
\hline & 180,5 & 230 & 2 & 237,5 & 224 & 5 \\
\hline & 180,3 & 232 & 2 & 236,8 & 225 & 5 \\
\hline & 181,5 & 233 & 2 & 239,2 & 223 & 5 \\
\hline & 179,4 & 229 & 2 & 240,9 & 224 & 5 \\
\hline & 181,1 & 228 & 2 & 238,8 & 226 & 5 \\
\hline & 182,2 & 234 & 2 & 241,3 & 224 & 5 \\
\hline & 181,4 & 231 & 2 & 240,8 & 225 & 5 \\
\hline & 180,3 & 232 & 2 & 237,7 & 225 & 5 \\
\hline & 182,3 & 231 & 2 & 236,8 & 223 & 5 \\
\hline & 179,6 & 231 & 2 & 239,5 & 224 & 5 \\
\hline & 183,8 & 228 & 2 & 237,7 & 223 & 5 \\
\hline & 180,4 & 232 & 2 & 238,4 & 218 & 5 \\
\hline & 178,3 & 231 & 2 & 236,8 & 216 & 5 \\
\hline & 179 & 229 & 2 & 237,5 & 221 & 5 \\
\hline \multirow{15}{*}{3} & 236,8 & 228 & 3 & 340,4 & 212 & 4 \\
\hline & 235,6 & 228 & 3 & 348,6 & 210 & 4 \\
\hline & 235,8 & 231 & 3 & 339,1 & 210 & 4 \\
\hline & 238,9 & 232 & 3 & 342,2 & 205 & 4 \\
\hline & 233,4 & 228 & 3 & 347,6 & 206 & 4 \\
\hline & 236,8 & 229 & 3 & 345,7 & 208 & 4 \\
\hline & 235,1 & 228 & 3 & 348,2 & 206 & 4 \\
\hline & 236,6 & 231 & 3 & 340,3 & 209 & 4 \\
\hline & 236,9 & 231 & 3 & 344,2 & 205 & 4 \\
\hline & 235,2 & 227 & 3 & 348,3 & 207 & 4 \\
\hline & 236,9 & 232 & 3 & 344,2 & 206 & 4 \\
\hline & 238,4 & 228 & 3 & 345,8 & 204 & 4 \\
\hline & 237,9 & 231 & 3 & 346,3 & 202 & 4 \\
\hline & 236,5 & 229 & 3 & 344,9 & 208 & 4 \\
\hline & 238,2 & 227 & 3 & 346,3 & 208 & 4 \\
\hline
\end{tabular}


Minitab 17 software program and variance analysis "ANOVA" test was used for the statistical assessments of the results. The data was considered at the level of $\alpha=0,05$ for determining the effect and significance levels of the factors examined. For the cases where the factor affects were significant.

\section{RESULTS AND DISCUSSION}

In the study, polyurethane and cellulosic paints were applied in 3 different application types. Coating thickness, surface hardness and impact deformation tests were performed with different amount of paint applied to the surface. The results were compared with each other for both types of paint and the optimum application plan according to the type of application was investigated.

(Table 4) displays average layer hardness, coating thickness and impact values for finish types and application types.

Table 4: Average layer hardness, coating thickness and impact values for finish types and application types.

\begin{tabular}{|c|c|c|c|c|c|}
\hline $\begin{array}{l}\text { Panel } \\
\text { Type }\end{array}$ & Finish Type & $\begin{array}{c}\text { Application } \\
\text { Type }\end{array}$ & $\begin{array}{c}\text { Average } \\
\text { coating } \\
\text { thickness }(\mu)\end{array}$ & $\begin{array}{c}\text { Average } \\
\text { Hardness } \\
\text { Value }\end{array}$ & $\begin{array}{l}\text { Impact } \\
\text { Value }\end{array}$ \\
\hline \multirow{6}{*}{ MDF } & \multirow{3}{*}{$\begin{array}{c}\text { Cellulosic } \\
\text { Paint }\end{array}$} & 1 & $179(4,71)$ & $241,67(9,5)$ & 3 \\
\hline & & 2 & $180,67(9,87)$ & $230,8(6,27)$ & 2 \\
\hline & & 3 & $236,67(4,95)$ & $229,53(3,89)$ & 3 \\
\hline & \multirow{3}{*}{$\begin{array}{c}\text { Polyurethane } \\
\text { Paint }\end{array}$} & 1 & $167,33(1,76)$ & $212,93(3,63)$ & 4 \\
\hline & & 2 & $238,67(11,25)$ & $222,13(11,3)$ & 5 \\
\hline & & 3 & $344,67(7,04)$ & $207,6(5,47)$ & 4 \\
\hline
\end{tabular}

(Number in parenthesis is standard deviations value).

According to the results as seen in Figure 1 and Figure 2; (1) the highest coating thickness using cellulosic and polyurethane paint applications with application type-3 was obtained as $236 \mu$ and $344 \mu$, respectively; (2) The highest pendulum hardness value was $241 \mathrm{~s}$ and $222 \mathrm{~s}$ for application type- 1 and application type-2, respectively; (3) The highest value of impact deformation was obtained by application type-3 and application type -2 as 3 and 5 respectively in cellulosic and polyurethane paint applications.

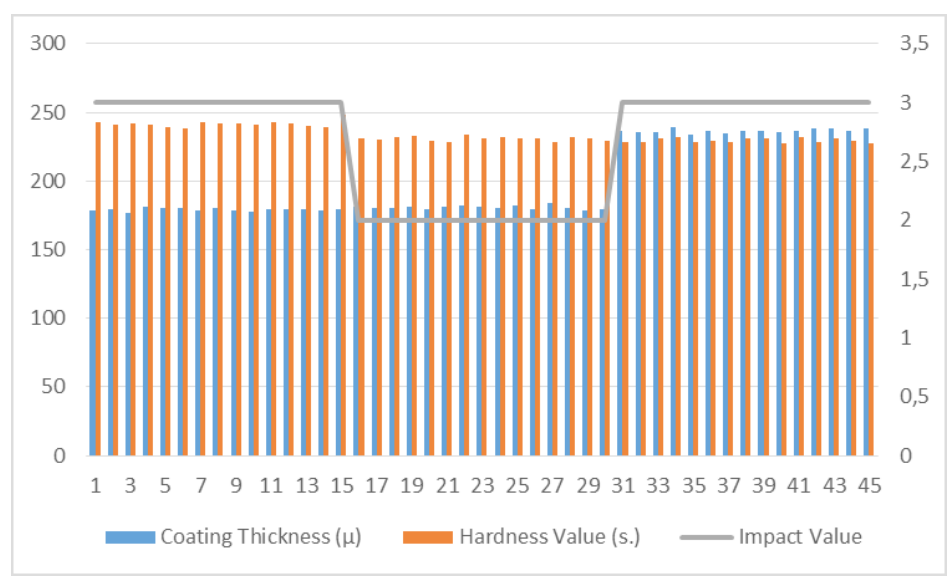

Figure 1: Coating performance values for cellulosic paint.

(Samples 1-15, 16-30, 31-45 represent application type 1, type2, type3 respectively) 


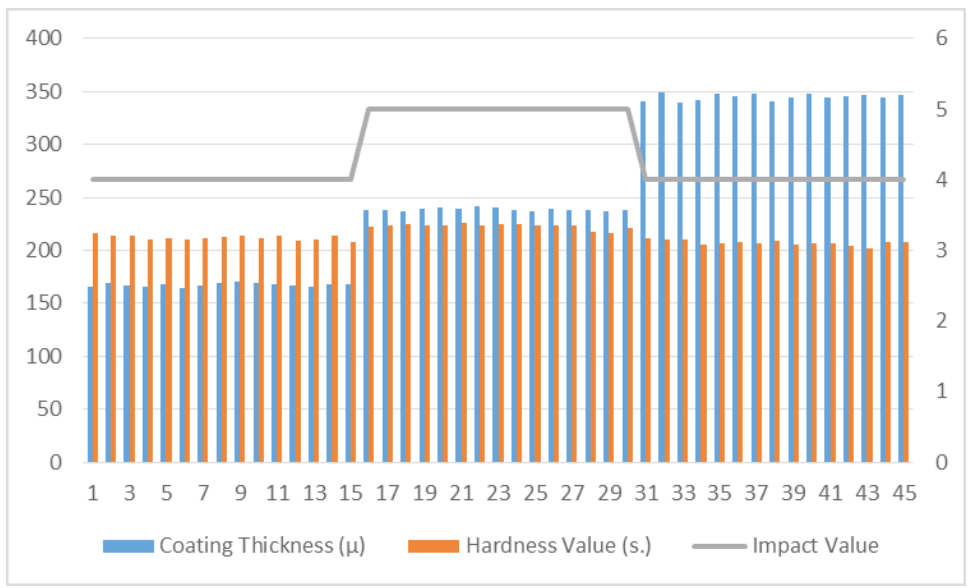

Figure 2: Coating performance values for polyurethane paint.

(Samples 1-15, 16-30,31-45 represent application type 1, type2, type3 respectively)

Surface treatment applications carried out with different layer thicknesses and paint types with hardness values are assessed with ANOVA analysis. The results are shown in (Table 5). The results are assessed statistically with $95 \%$ confidence level. As a result of the ANOVA analysis, the paint type, the layer thickness and paint type-layer thickness interaction were significant $(\mathrm{p}<0,05)$.

Table 5: Analyze of Variance:Coating Hardness versus Paint Type; Application Type.

\begin{tabular}{|c|c|c|c|c|c|}
\hline Source & DF & Adj SS & Adj MS & F-Value & P-Value \\
\hline Paint Type & 1 & 8801 & 8801,11 & 166,52 & 0,000 \\
\hline Application Type & 2 & 1394 & 696,88 & 13,18 & 0,000 \\
\hline $\begin{array}{c}\text { Paint } \\
\text { Type*Application } \\
\text { Type } \\
\end{array}$ & 2 & 1562 & 781,14 & 14,78 & 0,000 \\
\hline Error & 84 & 4440 & 52,85 & & \\
\hline Total & 89 & 16197 & & & \\
\hline
\end{tabular}

The main effects obtained according to the results appearing from the surface treatment applications carried out on the MDF panel are shown in Figure 3. In terms of the paint types, the pendulum hardness values of the cellulosic paint were better than the polyurethane paint. 


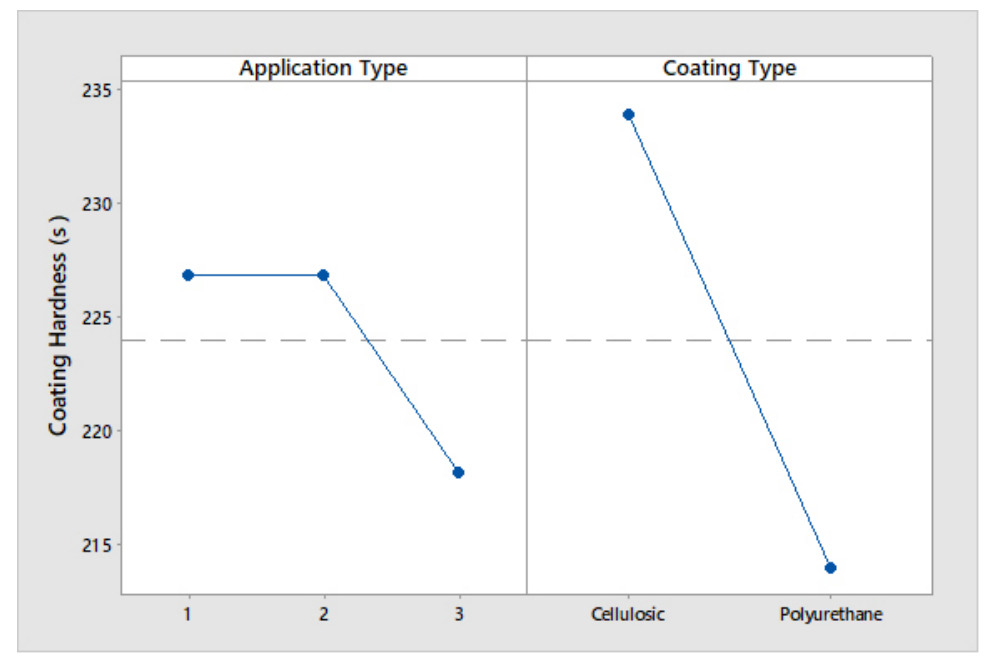

Figure 3: Main effects for coating hardness.

Main effect values of coating hardness for application type 1, 2 and 3 were 226,8 s 226,8 s and 218,2 $\mathrm{s}$ respectively while main effect values for Cellulosic and Polyurethane Paint types were $234 \mathrm{~s}$ and $214 \mathrm{~s}$ respectively. The results obtained from the surface treatment parameters with interaction are as shown in Figure 4. Cellulosic and polyurethane paints were performed as application 1,2 and 3. The results for cellulosic paints for application 1, 2 and 3 were 241,667 s 230,8 s and 229,533 s respectively. The results for polyurethane application 1, 2 and 3 were determined as 212,933 s 222,133 s and 207,6 s respectively.

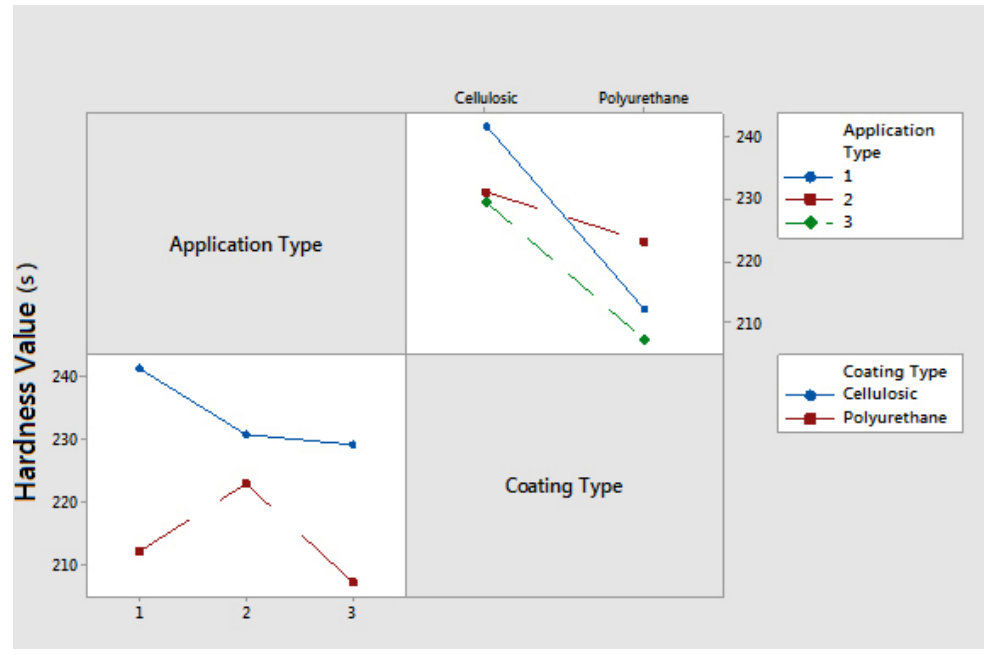

Figure 4: Interaction for coating hardness.

Cellulosic paint provided better results for coating hardness compared to polyurethane paint in applications made with application type 1 . In the application type 3 , cellulosic and polyurethane applications provided similar results.

In the study, paint type and application type, the factors whose effects on the hardness resistance were examined, are evaluated by applying variance analysis (ANOVA). In this analysis, the variable model explanation level is found as $72,59 \%$ (R-sq), Adj-R-sq $(70,96)$.

The relation between rapid impact hardness and layer hardness is given in Figure 5. For rapid impact hardness, the highest value was determined for type 2 polyurethane application and the lowest value was determined for type 2 cellulosic paint. 


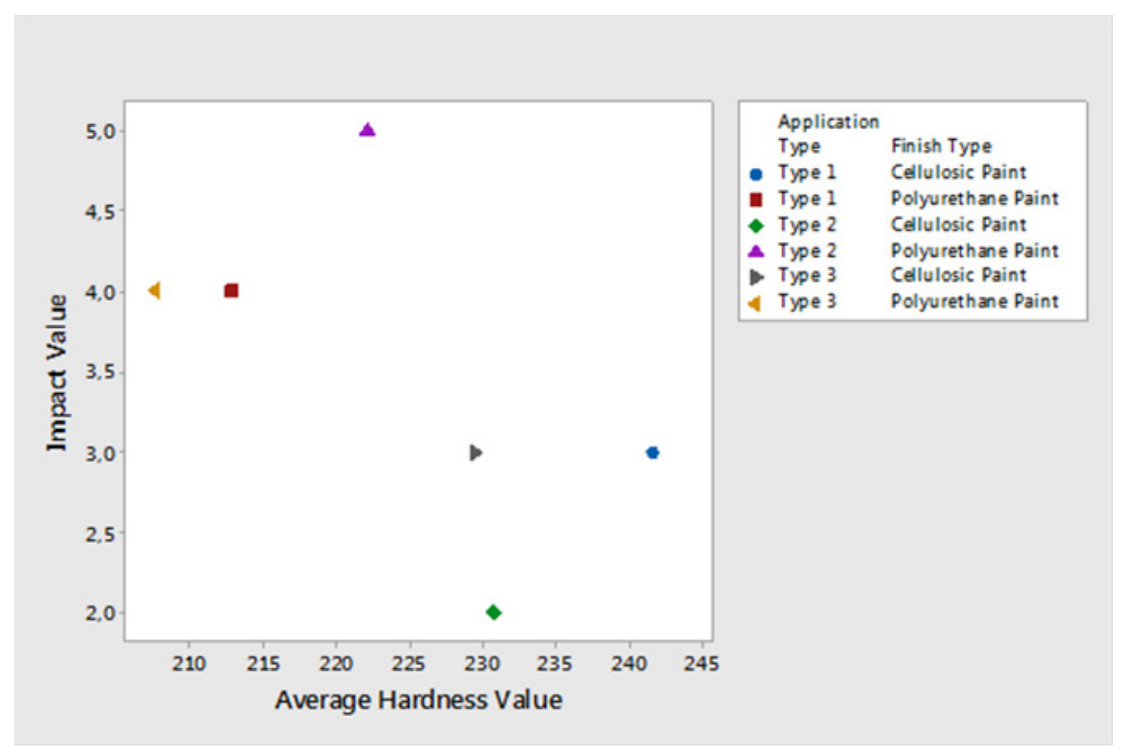

Figure 5: Relation Scatter plot of Impact Value and Average Hardness Value.

\section{CONCLUSIONS}

The surface hardness values are expected to increase in general when the layer thickness is increased in surface treatment applications. According to the results of the study, there are significant differences when the interactions between the paint and number of layers are considered. Therefore, different application thicknesses should be determined for different paint types for the properties expected from the surface treatment.

As the result of this study, layer hardness values for cellulosic paint were higher with respect to the values obtained from polyurethane paint. On the other hand, for impact deformation test, values of polyurethane paint were higher than cellulosic paint application. This result is considered to have a relation with the flexibility of the polyurethane paint.

Results of the previous studies suggest the need for right application methods at the right place for high quality surface coating applications. Waste values and cost of the surface coating applications are the topics for discussion. Working with less layers would shorten the time of applications, as well as reduce the costs. Thus, the surface coating parameters such as paint type and layer thickness should be determined optimally for ensuring the targeted surface coating performance.

\section{ACKNOWLEDGEMENTS}

This study is supported by Scientific Research Projects Coordination Unit of Istanbul University with project no. 46782 .

\section{REFERENCES}

Acda, M.N.; Devera, E.E.; Cabangon, R.J.; Ramos, H.J. 2012. Effects of plasma modification on adhesion properties of wood. International Journal of Adhesion \& Adhesives 32(1):70-75. 176.

Ahola, P. 1991. Adhesion between paint and wood substrate. Surface Coatings International 74(5): 173- 
American Society for Testing and Materials. ASTM. 1984. Standard Test Methods for Hardness of Organic Coatings by Pendulum Test ASTM D 4366-95. 1984. American Society for Testing and Materials: West Conshohocken, PA.

Bulian, F.; Graystone, J.A. 2009. Wood Coating Theory and Practice. Elsevier Science Ltd.: Amsterdam.

Cool, J.; Hernández, R. E. 2011. Improving the sanding process of black spruce wood for surface quality and water-based coating adhesion. Forest Products Journal 61(5): 372-380.

Darmawan, W.; Nandika, D.; Noviyanti, E.; Alipraja, I.; Lumongga, D.; Gardnes, D.; Gerardin, P. 2018. Wettability and bonding quality of exterior coatings on jabon and sengon wood surfaces. $J$ Coat Technol Res 15(1):95-104.

de Moura, L.F.; Hernandez, R.E. 2006. Effects of abrasive mineral, grit size and feed speed on the quality of sanded surfaces of sugar maple wood. Wood Sci Technol 40(6): 517-530.

Dilik, T.; Erdinler, S.; Hazir, E.; Koç, H.; Hiziroglu, S. 2015. Adhesion strength of wood based composites coated with cellulosic and polyurethane paints. Advances in Materials Science and Engineering 2015: $1-5$

Evans, P.D.; Haase, J.G.; Seman, A.S.B.M.; Kiguchi, M. 2015. The search for durable exterior clear coatings for wood. Coatings 5(4): 830-864.

Gorgun, H.V.; Dundar, T. 2018. Strength grading of Turkish black pine structural timber by visual evaluation and nondestructive testing. Maderas-Cienc Tecnol 20(1):56-64.

Gurleyen, L.; Ayata, U.; Cakıcier, N. 2017. Effect of heat treatment on the adhesion strength, pendulum hardness, surface roughness, color and glossiness of Scot pine laminated parquet with two different types of varnish application. Maderas-Cienc Tecnol 19(2):213-224.

Hysek, S.; Trgala, K.; Fidan, H.; Panek, M.; Lexa, M.; Bohm, M.; Veverka, J. 2018. Ultrasound measurement of exterior wood coating thickness. Maderas-Cienc Tecnol 20(4): 671-680.

International Organization for Standardization. ISO. 2017. Furniture-Tests for surfaces-Part 4.Assesment of resistance to impact. ISO 4211-4. 2017.

Jocham, C.; Schmidt, T.W.; Wuzella, G.; Teischinger, A.; Kandelbauer, A. 2011. Adhesion improvement of powder coating on medium density fiberboard (MDF) by thermal pre-treatment. Journal of Adhesion Science and Technology 25(15):1937-1946.

Kaygin, B.; Akgün, E. 2008. Comparison of conventional varnishes with nanolacke UV varnish with respect to hardness and adhesion durability. Int J Mol Sci 9(2):476-485.

Keskin, H.; Tekin, A. 2011. Abrasion resistance of cellulosic, synthetic, polyurethane, waterborne and acidhardening varnishes used woods. Construction and Building Materials 25(2):638-643.

Landry, V.; Blanchet, P.; Cormier L.M. 2013. Water-based and solvent-based stains:Impact on the grain raising in Yellow Birch. BioResources 8(2):1997-2009.

Montero, M.J.; de la Mata, J.; Esteban, M.; Hermoso, E. 2015. Influence of moisture content on wave velocity to estimate the mechanical properties of large cross- section pieces of structural use of Scots pine from Spain. Maderas-Cienc Tecnol 17(2):407-420.

Nejad, M.; Cooper, P. 2011. Exterior wood coatings. Part-2: modeling correlation between coating properties and their weathering performance. Journal of Coatings Technology Research 8(4):459-467.

Nejad, M.; Ung, T.; Cooper, P. 2012. Effect of coatings on ACQ preservative component distribution and solubility after natural weathering exposure. Wood Sci Technol 46(6):1169-1180.

Nejad, M.; Shafaghi, R.; Hiba, A.; Cooper, P. 2013. Coating Performance on Oil-heat Treated Wood 
for flooring. BioResources 8(2):1881-1892.

Pandey, K.K.; Sirinivas, K. 2015. Performance of polyurethane coatings on acetylated and benzoylated rubberwood. Eur J Wood Prod 73(1):111-120.

Pavlic, M.; Kricej, B.; Tomazic, M.; Petric, M. 2004. Selection of Proper Methods for Evaluation of Finished Interior Surface Quality. Copenhagen: COST E-18.

Ramananantoandro, T.; Eyma, F.; Belloncle, C.; Rince, S.; Irle, M. 2018. Effect of machining parameters on raised grain occurring after the application of water-based finishes. European Journal of Wood and Wood Products 76(4):1323-1333.

Salca, E.A.; Krystofiak, T.; Lis, B.; Mazela, B.; Proszyk, S. 2016. Some coating properties of Black Alder wood as a function of varnish type and application method. Bioresources 11(3):7580-7594.

Salca, E.A.; Krystofiak, T.; Lis, B. 2017. Evaluation of selected properties of Alder wood as functions of sanding and coating. Coatings 7(10):176-186.

Sogutlu, C.; Nzokou, P.; Koc, I.; Tutgun, R.; Döngeş, N. 2016. The effect of surface roughness on varnish adhesion strength of wood materials. Journal of Coating Technology and Research 13(5):863-870. 